\title{
Lebanese Investors' Decision Making Analysis from Conventional and Behavioral Perspectives Simultaneously
}

\author{
Latifa Ghalayini ${ }^{1} \&$ Sally Ziad Alkees ${ }^{2}$ \\ 1Faculty of Economic Sciences and Business Administration, Lebanese University, Beirut, Lebanon \\ ${ }^{2}$ Political sciences and Business administration, Lebanese University, Beirut, Lebanon \\ Sally.alkiis@st.ul.edu.lb
}

\begin{abstract}
The investment decision Process varies from one individual to another and from one country to another respectively. These decisions are usually taken based on either a Conventional basis or linked to the sentimental side of investors and reflected through behavioral finance gateway, where biases and psychological side of investors control their way of thinking and affect their investment decisions endlessly. Furthermore, based on previous literature the majority of investors tend to incorporate both gateways during their investment process as they don't depend solely on Conventional gate, but their psychological part appears to play a big role while deciding and similarly for Lebanon. However, the main aim of this paper lies in investigating the main factors from both gates triggering Lebanese individual investors' decision-making during their investment process. Moreover, the empirical part lies on focusing on a bunch of samples from individual Lebanese investors distributed along with most Lebanese districts; where 211 complete responses are interpreted within the SPSS program, undergoing factor analyses and Regression models. Results obtained indicates that Lebanese individual investors tend to incorporate both gateways in their investments decision, where the main goal stays utility and profit maximization; that to say tending to seek profits regardless of the investment field and approach. Nevertheless, during seeking profits Lebanese investor is being exposed to certain behavioral errors and biases that appear to impact and control his decisions significantly during investment making the process so far, and theses biases are affecting the Lebanese individual investors clearly more than that of conventional ones.
\end{abstract}

Keywords: Opportunity Cost, behavioral biases, mental accounting, Regret aversion, overconfidence, Utility maximization, Social cause enhancement.

\section{Introduction}

Opportunity cost is considered as one of the most important decision cost concepts by many economics mainly in London by the 1930s (Edward, 1937). Moreover, individual choices during the decision-making process were based on the opportunity cost concept, where each investor adopts a unique way of thinking to take his own choice which he believes that it's the perfect one for him and he cannot transfer it to other's knowledge. As a result, Hayek in 1935 suggested that the concept of Opportunity cost shall be utilized for demonstrating the inconceivability within ideal socialist calculations so far. However from the other side "Behavioral Finance becomes a basic part for decision-making process where it highly impacts investors' performance" (Barberis \& Thaler, 2003). Parikh has recalled also in 2011 that "An understanding of how feelings and emotions lead to irrational behavior which is essential for any investor". As a result, in-depth education regarding the different biases that may be faced is very needed to all investors, in order to know how to face them whenever they have been surprised with, to obtain a more effective and efficient work.

Furthermore; investors usually do lots of mistakes without recognizing, a simple example regarding what is mentioned previously is when investors hold on for a long period while facing big losses, not regretting or waiting for any happy news that would reverse the entire situation. As a result, Parikh (2011) had discovered a global key that helps investors to make the right decision which lies in combining both sound judgment skills along with emotional regimen, and so they obtain the aimed rational and sound behaviors. Moreover, It is noticeable to mention that Lebanese investors are being faced with various types of investments where they usually prefer bending toward family investments or joint ones to minimize the risk level that they may be encountered to a way forward; additionally to social responsibility investments that appeared recently and addressed in a separate article accordingly under the title of "Social Responsibility investments in Lebanon"; where "Social responsibility investment advocates mainly Charity investment; where it tends to spread worldwide especially using pension funds, as 2008 financial crises have been the main push toward ethical financial tools. 
Which focuses mainly on "social and environmental investments" (Baron, 2001). This paper examines the reality behind Lebanese investment decision-making through studying factors affecting their decision-making process from both sides; as a section from a circulated questionnaire in arrange to handle divergent views for several individual Lebanese investors spread all over Lebanon. Acquired figures are inserted, analyzed and interpreted through SPSS. Nevertheless, the paper is directed as follows: the theoretical Framework of decision-making is presented in the Second Section. Furthermore, the Third Section focuses on the used methodology moving to the fourth Section that presents data analysis of Lebanese individual investors. Section 5 presents the Test results and analysis pertaining to Lebanese individual investors' decision making; to end up with a general conclusion conducted in section 6 .

\section{Theoretical Framework behind Lebanese Investors' Decision Making}

The study of decision behavior is based on the comprehension of circumstantial elements; which stands as a theoretical framework known by "Expectancy Decision Processing Model", that is build based on behavioral decision theories, in addition for REMM model accompanied with agency theories and appropriation for opportunity cost concept during unlike decision states, which is suggested by both (Watts and Zimmerman, 1990). The Expectancy Decision Processing Model has been developed using the help of the REMM model along with Expectancy Theory and behavioral Decision Theories, additionally to Theory of Choice which stands as the corner base for opportunity cost concept. The core framework for model analysis is as follows; taking into account the primary presumption that decision-maker (investor) already built in his mind and focuses on a certain or adjusted choice objective, where it's debated that decision taker tends to adjust either the situation for factors' existing under concern, or selected choices regarding a behavioral decision or both; for obtaining bigger chances of accomplishing the already set objective. Based on the selected approach that lies under opportunity cost and is utilized during the investment decision-making process, it can be clearly noticed that the opportunity cost approach is considered as one of the numerous costing approaches that are cited and utilized by decision-makers.

Additionally, it's clearly realized that distinctive costing approaches lead to diversified results (Clark, 1923). Furthermore, those types of cost stand for being real indicators during the prioritization process of different preferences among various decision options; where distinctive cost models provide a certain distinctive positioning list along with an option set list in different positions. Furthermore, the elected/option that may stand first with respect to a certain specific model would as well stands in a lower position while implementing another cost model. Therefore, the appropriation for a certain specific cost approach and model results in a real effect on the finalized selection and adaptation for a particular resolution alternative and borrowing of a specific decision behavior expressed by the decision taker himself. Nevertheless, "Previously done researches recommended that decision behavior techniques are a loop for task characteristics, along with decision-maker characteristics additionally for the reaction between both of them (Hogarth and Reder, 1987)". Furthermore; taking to account the numerous existing variables, the main measurement tool/ratio that stands to be very useful and essential; especially when various investment choices are available and selection must take place during the decision making process, stands to be the Opportunity cost measurements (Gul, 1984).

However, During 2008, various studies toward this issue started appearing, emerging with the business students (Chira, Adams and Thornton) that acquired the curiosity to investigate how specific errors impact them; where there existed about 68 surveys and disseminated to undergraduate and graduate business students at Jacksonville University- the USA where researchers prevailed that students are not so much exposed to act in an overconfident and excessive Optimism, whereas on the contrary objectivity has restrained their decisions. Moving to the Nairobi Stock Exchange; Waweru, Munyoki, and Uliana (2008) that "have studied how institutional investors have been impacted by specific behavioral variables such as Herding, representativeness, overconfidence, anchoring, loss aversion and availability bias during taking their investment decisions using a Questionnaire". Thus "various debates rose to investigate about the choice of different practices that helps in identifying the utilization of the opportunity cost idea in business choices; as it is uncertain if the concept is adopted in practices by managers and executives" (Frederick, et al., 2009). Nevertheless, they have focused on studying the effects of constraint on opportunity cost consideration without any previous reminders for consumers or investors. 
By adopting two versions of the scenario targeting 194 students to know the way of their decision making (constrained version and unconstrained version) with the help of two independent coders blind to hypotheses and conditions where they coded their responses; to get that constrained individuals to consider their opportunity costs more frequently than unconstrained individuals and those who considered opportunity costs were more sensitive to their value. Nevertheless, Spiller (2011) addresses research to know where consumers consider opportunity costs, and what are the consequences of considering opportunity costs, investigating whether consumers should incorporate opportunity costs into every decision they make, using online surveys targeted more than 400 people, where it appeared to be that Consumers who consider opportunity costs are less likely to buy focal options than those who do not when opportunity costs are attractive. As Stated by Sinha (2012) "a new crisis raised in the form of Sovereign debt which was initially originated in Europe to spread all over the world, hitting all the financial markets consequently". Nevertheless "Volatility has been the most famous word that controlled the prices of the financial markets starting since 2008; horrible movements have taken place in prices due to the extreme fear and anticipation of the investors, which turned the life for all kind of investors upside down".

Hence markets begin to end day after day and so understanding the irrationality within investors' behaviors has been clearer and the reasons lying behind become well known. Moreover, the core problem is found in numerous numbers of psychological biases which are impacting investors' behaviors leading to irrational thinking during the decision-making process. Subsequently, Zhang (2013) explored cultural differences between Chinese and European Canadians in considering opportunity cost while making purchase decisions, taking into account mainly individual differences in the habit of considering opportunity cost using Two different scenarios to decide whether to buy a single product or not on 121 Euro-Canadians and 119 Chinese, where results confirmed that Chinese were also more likely to mention the opportunity cost thoughts than did European Canadians while making the decision thus it can be confirmed that opportunity cost consideration varies, at least to some extent, across cultures. Lately, studied the impact of uncertainty on firm-level capital investment, and examines whether this effect depends on the degree of competition that firms face or other factors, focusing mainly on an empirical setting to construct a time-varying uncertainty measure that is exogenous to economic conditions and firm behavior, obtaining that higher uncertainty results in a decrease in investment for firms in more concentrated industries and on the other side it was concluded that the degree of competition plays an important role in the link Between uncertainty and investment.

\section{Methodology}

When making any research, two main approaches help in studying and verifying the studied theories which are "Deduction and Induction". Whenever, the researcher finds that his study usually starts with a certain theory, thus he tends directly to the Deductive approach and starts collecting empirical evidence that would support this theory and this thing is completely in contrast with the inductive approach that starts from empirical evidence to get a theory. However, the following paper aims to investigate the impact of opportunity cost and behavioral factors (biases) which would affect the majority of individual investors in a dissimilar way during uncertainty; therefore deductive approach seems to be the most appropriate. Moreover, we have noticed that our research starts to give an overview regarding opportunity cost's impact and behavioral finance on investor's decision making during uncertainty, based on different and various researches done before that contain their own or similar model and hypotheses to be studied, as a result, our own questionnaire have been built based on this previous literature. Moreover, the suggested hypotheses have been tested through the help of collecting various data to analyze them. Nevertheless, whenever talked about the Deductive method, it is noticed that the Quantitative method which is descriptive in nature and is used by researchers to understand the effects of various inputs on the individual investors and how do they react in return, is going to accompany it, in addition to various statistical methods to arrive together to generalize the tested hypothesis and prove that opportunity cost accompanied with numerous biases can affect an individual's investment decision taking in an uncertain environment so far.

Data Source: The Data used in this paper is collected based on a questionnaire distributed to target different Lebanese investors all across Lebanon. The core aim of this paper is to target mainly individual investors (males and females) ages varies from 22 years old and more; as individual investors could be either young 
and are still fresh investors, or mature one's that have enough experience in this field; in order to realize the difference between them and how would years of experience in the field affect mainly the decision taken.

Sample Frame and Size: In this paper probability sampling technique mainly "Random Sampling" is adopted, as this type looks after diversified categories from investors distributed among different regions in Lebanon, for ensuring Representativeness and precision toward the obtained results; through utilizing Simple random sampling technique, where each included sample has the same specific probability to be chosen, which in turn characterizes it for being more accurate and would help in testing hypotheses under study in order to generalize results obtained all over the population; as a result, the questionnaire was sent via a link to tackle the biggest number of investors in order to obtain different views to validate and ensure credibility to the paper. Nevertheless, the utilized sample profile is based on a diversified judgmental criterion like respondents' age, Experience, most investment preferable market, additionally for the most preferred range of prices to invest in. Moreover, The study targets individual investors (males and females) starting from 22 years old and above, where these kinds of investors could be either young (unexperienced) or the ones acquiring enough experience in the domain to compare differences lying between them and how would years of experience affect the decision taken additionally for main choices seeking toward.

Hypotheses Under Study: Various hypotheses have been tested throughout this study to tackle the reality of Lebanese investor's decision-making and whether they are more likely exposed to conventional finance ways or to other psychological parts which fall under behavioral finance attributes. However, based on this several hypotheses were under study.

H1: All types of individual investors are affected by certain behavioral biases during decision-making.

H2: Most of the investors tend to be more overconfident and have excessive optimism while taking decisions regarding their portfolios.

H3: Most of the investors tend to face representativeness bias.

H4: Most of the investors tend to face Herding bias during decision making.

H5: Investors usually feel in fear to get out from their investment even if they knew that it's a losing one.

H6: All types of individual investors tend to face Mental accounting bias.

H7: Most individual investors tend to face cognitive Dissonance bias.

H8: Transaction cost theory is taken into consideration during decision-making.

H9: Utility maximization is the main target of Lebanese individual investors.

H10: Social Cause enhancement is one of the main goals during investment decision-making.

H11: Agent-principle theory is taken into consideration during the decision-making process.

H12: Satisfaction level and motivation process play a big role during decision making.

H13: Value judgment is taken into consideration during the decision-making process.

H14: ROI/ROE ratios are taken into consideration during the investment decision process, thus investing in high debt companies to maximize profits.

Data Analysis: The used questionnaire construct from 29 questions where obtained sample registered 211 complete respondents. The questionnaire was sent through a link to individual investors ranging between 22 years old and above out of which 211 questionnaires were sent back. Moreover, the utilized questionnaire is decomposed into three main sections: starting with demographics questions, moving to investments basic and finally questions related to different investment decisions and behavioral biases that would be faced by various investors. Furthermore, investors are being questioned to respond based on a continuous scale where some of them follow the Five-Points Likert based scale while others follow the three-point Likert scale.

Quality Criteria: Any research study is not considered appreciated until it meets the Quality requirements that business research should acquire. For that we were interested in studying basics criteria that may support the keys of scientific research so far, which are Reliability and Validity, however, Validity has been expressed via measuring internal, external and ecological validity. While reliability is verified while studying stability and internal reliability across all inter-observer consistency.

Validity: Validity is demonstrated through four basic points which are: measurement, internal-external and ecological validity (Bryman \& Bell, 2011, p.42). 
$\checkmark$ Measurement validity as Bryman and Bell (2011, p.165) states that questions that are found in the questionnaire can be considered true for measuring the targeted concept; however our questionnaire was built mainly on previous used theoretical models pertaining to previous studies, moreover, various indices have been applied to show the real image of different behavioral factors that could influence individual's investor's decision making. However, using the Likert scale in our questionnaire increases the accuracy of our measurement, in addition, that all of our collected data has been analyzed and processed through SPSS software in order to obtain the main factors that can affect individual's investor's opinions while taking his decision and their correlations; As a result measurement validity was obtained in our study.

$\checkmark$ Internal validity was obtained in this research due to the unpremeditated relation existing between independent (Biases) and dependent ones (Decision taken); however the strong correlation between the different biases and the dependent one was just considered after testing, therefore internal validity was spread all over the research.

$\checkmark$ External validity, however because of the random sampling that we have chosen in our study to obtain to a certain extent a relatively large sample through choosing different random respondents all across Lebanon to generalize outcomes over the population.

$\checkmark$ Ecological validity focuses on question to discover whether obtained outputs are eligible or applicable to people's every day (Bryman \& Bell, 2011, p.43)", however, our questionnaire was designed to tackle different opinions from different respondents and to know approximately the real reactions of how an individual investor would behave when faced with such cases, therefore we can tell that our research can give to a certain extent a general overview about an investor daily life.

\section{Reliability Test Results}

Table 1: Reliability Test Result-Overall

\begin{tabular}{lll}
\hline $\begin{array}{l}\text { Reliability Results } \\
\text { Cronbach's Alpha }\end{array}$ & $\begin{array}{l}\text { Cronbach's Alpha Based on Standardized } \\
\text { Items }\end{array}$ & N of Items \\
\hline 0.612 & 0.624 & 18 \\
\hline
\end{tabular}

Source: The author

The reliability test results obtained in the above table indicates $62 \%$ reliability which is considered as an acceptable percentage indicating internal reliability, but from the other side it is also considered "Questionable" to a certain extent and this is very normal in our case since Cronbach's alpha measures the internal consistency of the scale and therefore used mostly when the study contains a questionnaire based on Likert scale questions and researcher wishes to test if the scale used is reliable or not. However in this study there exists various response formats such as the five-Likert scale, three-Likert scale and others were closedended; so it's very normal for Cronbach alpha to be questionable in our case due to the absence of unification of the utilized Likert scale all over.

Table 2: Descriptive Statistics-Overall

\begin{tabular}{lllllll}
\hline & $\mathbf{N}$ & Minimum & Maximum & Mean & Std. Deviation & Variance \\
\hline Sex & 211 & 1 & 2 & 1.45 & .498 & .248 \\
Age & 211 & 1.00 & 4.00 & 2.5071 & .65734 & .432 \\
Years of investment & 211 & 1 & 31 & 12.48 & 6.378 & 40.679 \\
Preferred market & 211 & 1 & 2 & 1.46 & .500 & .250 \\
Investing Choice & 211 & 1 & 5 & 2.06 & .895 & .801 \\
Preferable Price range & 211 & 1.00 & 3.00 & 1.9289 & .78659 & .619 \\
Valid N (listwise) & 211 & & & & & \\
\hline
\end{tabular}

Source: Prepared by the Author 


\begin{tabular}{l} 
Journal of Economics and Behavioral Studies (ISSN: 2220-6140) \\
Vol. 13, No. 4, pp. 50-59, August 2021 \\
\hline \hline
\end{tabular}

Above is a descriptive statistics table pertaining to basic demographics and investment results. We were interested in studying the mean, std. deviation and variance and the above results were obtained.

\section{Results and Analyses}

Detailed Results' analysis pertaining to the obtained results from different Tests is presented below.

Correlations: While investigating the correlation among dependent variables (decision making) and independent ones (Opportunity Cost variables, uncertainty and behavioral biases variables: Overconfidence, Representativeness, Herding, Anchoring, Regret aversion, mental accounting, and Cognitive dissonance...) results' obtained were as follow: Satisfaction level was positively correlated with taking an investment decision at the level of (0.05) where Pearson correlation between the two indices registered 0.154 and significant at 0.05 (positive correlation). Social cause enhancement was positively and highly correlated with taking an investment decision at 0.05 levels with 0.193 Pearson correlations (positive correlation). Utility maximization and the dependent index have a high and positive correlation (0.333) significant at 0.01 , thus it can be said that the main goal for an investor is maximizing his utility and profits no matter the investment way. However, pertaining to ROI/ROE measures was correlated negatively with decision making (-0.048) and not significant.

Meaning that Lebanese individual investors don't look for numbers and previous studies in most cases but there is another part that is interfering during the decision-making process. Furthermore, the agent-principle relation was negatively correlated with investment decision making $(-0.05)$, investor preference $(-0.137)$ and Value judgment $(-0.108)$, Transaction cost theory measurement $(-0.151)$ they were negatively correlated with decision making. Furthermore, the Lebanese mind state while facing a loss (which falls under the mental accounting variable) appears to be highly correlated with taking an investment decision (0.216), that's to say a Lebanese investor is able to forget his losses once faced with a "Win". Nevertheless, Holding on to an investment not to regret later appears to be positively correlated and significant with decision making (0.184) whereas the other variables lying under behavioral finance variables (Representativeness, Hindsight, Gambler's fallacy and anchoring) is negatively and not significant as shown in the correlation table.

\section{Factor Analysis}

Table 3: KMO and Bartlett's Test-Overall

\begin{tabular}{lll}
\hline Kaiser-Meyer-Olkin Measure of Sampling Adequacy & $\mathbf{. 5 3 9}$ \\
\hline Bartlett's Test of Sphericity & Approx. Chi-Square & 138.763 \\
& Df & 45 \\
\hline
\end{tabular}

KMO and Bartlett's test varies usually between 0 and 1, Kaiser (1974) ensures that records more than 0.5 shall be valid for factor analysis to obtain reliable variables; whereas values less than 0.5 oblige researchers for collecting either more data or rethinking another time in the included and studied variables. In the table above Kaiser's value recorded 0.539 , which is considered "Acceptable" according to Hutcheson and Sofronie (1999), thus researchers shall be confident that the factor analysis technique is appropriate for the data collected. Moving to Bartlett's that tests a null hypothesis and shall be significant only if $(<0.05)$. However regarding the used data; Bartlett's test is highly significant $(\mathrm{p}<0.001)$ therefore it can be clearly confirmed that factor analyses are very appropriate for conducting the study way forward.

Regression (Model Building): Linear regression is conducted between independent factors and dependent ones (Opportunity Cost variables, and behavioral biases variables: Overconfidence, Representativeness, Herding, Anchoring, Regret aversion, mental accounting, and Cognitive dissonance...) and the dependent variable (investment decision making). 
Table 4: Model Summary-Overall

\begin{tabular}{lllll}
\hline Model & $\mathbf{R}$ & R Square & Adjusted R Square & Std. Error of the Estimate \\
\hline 1 & $.433^{\mathrm{a}}$ & .288 & .251 & .793 \\
\hline
\end{tabular}

a. Predictors: (Constant), Social Cause enhancement, Satisfaction level, Utility maximization, Value judgment, Overconfidence and excessive optimism, Agent/principle, ROI/ROE measurements, Investment preference, Hindsight, Herding, Representativeness, Anchoring, Regret aversion, Gambler's fallacy, Mental accounting. b. Dependent Variable: investment Decision taken.

Table 5: ANOVA ${ }^{\mathrm{b}}$-Overall

\begin{tabular}{lllllll}
\hline Model & & Sum of Squares & DF & Mean Square & F & Sig. \\
\hline 1 & Regression & 39.707 & 11 & 3.610 & 5.212 & $.000^{\text {a }}$ \\
& Residual & 137.819 & 199 & .693 & & \\
& Total & 177.526 & 210 & & & \\
\hline
\end{tabular}

a. Predictors: (Constant), Social Cause enhancement, Satisfaction level, Utility maximization, Value judgment, Overconfidence and excessive optimism, Agent/principle, ROI/ROE measurements, Investment preference, Hindsight, Herding, Representativeness, Anchoring, Regret aversion, Gambler's fallacy, Mental accounting

b. Dependent Variable: investment Decision taken

Table 4 shows that $\mathrm{R}$ square is equal to 0.288 indicating that $28.8 \%$ of the total variance in supporting investment decisions taken has been explained. Nevertheless, obtaining F significant for less than 0.05 suggests a specific linear Relationship amongst applicable variables and ensuring the significance of the overall model used and obtained so far.

Table 6: Coefficients ${ }^{\text {a }}$

\begin{tabular}{|c|c|c|c|c|c|c|}
\hline \multirow{2}{*}{\multicolumn{2}{|c|}{ Model }} & \multicolumn{2}{|c|}{ Unstandardized Coefficients } & \multicolumn{2}{|c|}{$\begin{array}{l}\text { Standardized } \\
\text { Coefficients }\end{array}$} & \multirow[b]{2}{*}{ Sig. } \\
\hline & & B & Std. Error & Beta & $\mathbf{t}$ & \\
\hline \multirow[t]{16}{*}{1} & (Constant) & 2.487 & .397 & & 6.265 & .000 \\
\hline & Hindsight & .107 & .152 & .048 & .704 & .483 \\
\hline & Herding & -.015 & .029 & -.035 & -.512 & .609 \\
\hline & Representativeness & .179 & .121 & .105 & 1.484 & .139 \\
\hline & Anchoring & .041 & .074 & .040 & .560 & .576 \\
\hline & Regret aversion & .171 & .073 & .164 & 2.322 & .021 \\
\hline & Gambler's fallacy & .254 & .086 & -.217 & -2.963 & .063 \\
\hline & Mental accounting & .270 & .081 & .234 & 3.320 & .001 \\
\hline & Social Cause enhancement & .060 & .079 & .052 & .758 & .044 \\
\hline & Satisfaction level & .095 & .069 & .092 & 1.378 & .170 \\
\hline & Utility maximization & .321 & .073 & .302 & 4.394 & .000 \\
\hline & Value judgment & -.068 & .063 & -.073 & -1.082 & .281 \\
\hline & $\begin{array}{l}\text { Overconfidence } \\
\text { excessive optimism }\end{array}$ & .082 & .130 & .041 & .628 & .031 \\
\hline & Agent/principle & -.606 & .249 & -.165 & -2.437 & .016 \\
\hline & ROI/ROE measurements & .116 & .079 & .095 & 1.469 & .143 \\
\hline & Investment preference & -.075 & .066 & -.076 & -1.137 & .257 \\
\hline
\end{tabular}

a. Dependent Variable: investment decision 
The way forward, Table 6 presents Factor analysis results indicating a negative, Relationship among the six independent factors, omitting eleven which are mentioned above but regression was made to confirm results. The relative importance for each independent variable presented in standardized terms is expressed by Beta. It is noticed that Hindsight, Representativeness, Anchoring, Regret aversion, gambler's fallacy, mental accounting in addition to Social cause enhancement, Satisfaction level, Utility maximization, Overconfidence \& excessive optimism, ROI/ROE measures indicates significance with dependent factor (investment decision making). However, The coefficient table supports in concluding the equation; while over viewing the T-test column, it is noticed that (Utility maximization, Mental Accounting, Regret Aversion, Over Confidence \&excessive optimism and Social cause enhancement) are significant while others are not with (beta $=0.321$, beta $=0.270$, beta $=0.171$, beta $=0.082$ and beta $=0.060$ ).

Model Estimation: Results indicate the relationship presented between Independent variables and dependent ones (Investment decision making) per the below:

$\mathrm{Y}=2.487+0.321$ Utilitymax+0.270mentalAcc+0.171 regretaversion+0.0820verConf+0.60Socialenhancment.

This result indicates that five independent variables from both sides (conventional and behavioral finance) affects significantly the dependent variable which is (Investment decision making of the Lebanese individual investor); where Utility maximization and Social cause enhancement lies under opportunity Cost variables; whereas Mental Accounting, Regret aversion and overconfidence reside under behavioral finance variables. However, Lebanese individual investors when being faced by various choices to choose from during decisionmaking process; they are exposed to face different factors that impact their decision taken from both sides (conventional and behavioral). Moreover, the main aim behind any decision lies in Utility maximization, followed by three biases that control their way of thinking and shall realize their high impact during taking the decision (Mental accounting. Overconfidence/excessive optimism and Regret aversion); in addition to enhancing socially responsible investments that appear to be a new trend, regarding the variables that affect the Lebanese investor decision making. These variables must be taken into account seriously, especially enhancing socially responsible investments that are becoming one of the main investment choices that a Lebanese investor would choose whenever faced with numerous investment choices.

\section{Summary for Findings}

$\checkmark$ Hypothesis one (H1) was accepted, where all types of individual investors are exposed to behavioral biases during taking decisions regarding their portfolios, where it is noticed while studying whether individual investors have heard about "Behavioral finance", the majority of them which record $51.7 \%$ appear to have a fair knowledge toward this concept.

$\checkmark$ Hypothesis two (H2) was also accepted, as we have found that $64 \%$ have been taking so far the right decision in their decisions and $75.4 \%$ build their portfolios according to its past performance and historical records, in addition to that this factor was the main contributor that has appeared when building our model.

$\checkmark$ Hypothesis three (H3) regarding facing Representativeness bias was rejected.

$\checkmark$ Hypothesis four (H4) regarding facing Herding bias was rejected.

$\checkmark$ Hypothesis five (H5) that was related to facing Regret aversion impacts highly and significantly in Lebanon, thus it was strongly accepted.

$\checkmark$ Regarding hypothesis six (H6) that talks about mental accounting bias tend to be highly significant $(\mathrm{P}>0.005)$ so hypothesis 6 is strongly accepted.

$\checkmark \quad$ Hypothesis seven (H7) regarding facing Cognitive dissonance bias was rejected.

$\checkmark$ The transaction cost theory is taken into account during the decision-making process, thus H8 is accepted.

$\checkmark$ Utility maximization is the most dominant factor that controls the way of thinking of the Lebanese investor (H9 is strongly accepted).

$\checkmark$ Hypothesis ten (H10) regarding enhancing socially responsible investments is one of the contributors that impact significantly the investors' decision-making in Lebanon, thus it is also strongly accepted.

$\checkmark$ Agent-principle theory is the main theory that a Lebanese individual investor takes into account during decision making; therefore $\mathrm{H} 11$ is accepted as well. 
$\checkmark \quad$ Hypothesis twelve (H12) regarding the effect of the rewarding process on decision making plays also a big role during decision making thus $\mathrm{H} 12$ is accepted.

$\checkmark \quad$ Value judgment contributes clearly during decision-making seeking for utility maximization and more profits, thus $\mathrm{H} 13$ is accepted also.

$\checkmark$ ROI/ROE wasn't the main ratio that the Lebanese investor looks for during his decision-making process, therefore $\mathrm{H} 14$ is rejected.

\section{Conclusion and Recommendations}

This paper assesses the different factors impacting Lebanese individual investors' decision-making, from both levels of Conventional and behavioral finance considering uncertainty. Thus this paper takes into consideration numerous variables which lie under opportunity cost factors; assuming that a cost must be paid whenever choices exist in an uncertain environment, additionally to the biases/errors that fall under behavioral or psychological considerations which in turn impact the investor's decision making so far. This paper ensures that Lebanese individual investors incorporate factors from both sides (traditional and psychological ones) during their decision-making process, but Utility maximization stays the main goal that a Lebanese investor seeks during any decision-making process. However, a combined theoretical model is conducted to address the simultaneous effect for both fundamentals and behavioral factors together. Results show that factors from both sides (conventional and behavioral) affecting the decision-making process for the Lebanese investors; Where the main goal stays utility and profit maximization; that to say tending to seek profits regardless of the investment field and way. Additionally during seeking profits, Lebanese investor is being exposed to certain behavioral errors and biases that appear to impact and control his decisions significantly during the investment making process so far.

Moreover and to recap; Mental accounting bias ensures that the mindset of the Lebanese investor is programmed to forget his losses whenever faced with gains or profits; overconfidence or excessive optimism factors ensures that the Lebanese investor lives on the glories of the past, so he tends to overestimate his abilities and skills leading him to face big risks in order to gain more and more, which in turns leads him to underestimate the overall situation. Moreover, Regret aversion affects significantly the decision-making process; as the latter holds on always his wrong investment choices even when being faced with continual loss; fearing regret that would control his life later especially if he has been working on so long. Thus, this paper ensures that Lebanese investors face factors from both sides (opportunity cost variables and behavioral one); more precisely it appears that the psychological part participates a lot in the decision making process than that of conventional one, where three factors (Mental accounting, Regret aversion, Overconfidence) is encountered in the model versus two from the fundamentals and falls under opportunity cost variables(Utility maximization and Social cause enhancement), therefore this paper ensures that Lebanese investors shall take into account seriously and be more aware their sentimental side which is leading them unconsciously to take risky and wrong decisions so far without realizing their dire consequences.

\section{References}

Baron, D. (2001). Private politics, corporate social responsibility and integrated strategy. Journal of Economics and Management Strategy, 10, 7-45.

Barberis, N. \& Thaler, R. (2003). A survey of behavioral finance. In: Constantinides, G., Harris, M. \& Stulz, R. (Eds.). Handbook of the Economics of Finance. North-Holland, Amsterdam.

Bryman, A. \& Bell, E. (2011). Business Research Methods, Third Edition, Oxford University Press.

Clark, B. J. (1908). The distribution of wealth: A theory of wages, Interest and profits, New York: Macmillan.

Edwards, R. (1937). The Rationality of Cost Accounting, in Plant, A (ed.), Some Modem Business Problems. (1937); Reprinted in Buchanan, J. \& Thirlby, G. (Ed), LSE Essays on Cost.

Frederick, S., Novemsky, N., Wang, J., Dhar, R., \& Nowlis, S. (2009). Opportunity cost neglect. Journal of Consumer Research. 36, 553-561.

Gul, F. (1984). The Joint and Moderating Role of Personality and Cognitive Style on Decision making. The Accounting Review, 59(2), 264. 


\section{Journal of Economics and Behavioral Studies (ISSN: 2220-6140)}

Vol. 13, No. 4, pp. 50-59, August 2021

Hogarth, R. M., \& Reder, M. W. (1987). Rational Choice: The contrast between economics and psychology. University of Chicago Press.

Hutcheson, G. \& Sofroniou, N. (1999). The Multivariate Social Scientist: Introductory Statistics Using Generalized Linear Models. Sage Publication, Thousand Oaks, CA.

Kaiser, H. F. (1974). An index of factorial simplicity. Psychometrika, 39, 31-36.

Parikh, D. (2011). Relative attributes. International Conference on Computer Vision (ICCV), 2011.

Sinha, C. (2012). Factors Affecting Quality of Work Life: Empirical Evidence from Indian Organizations. Australian Journal of Business and Management Research, 1, 31-40.

Sinha, S. and Back, L. (2012). Making methods sociable: dialogue, ethics and authorship in qualitative research. Journal of Qualitative Research, 14(4), 473-487.

Spiller, S.A. (2011): Opportunity Cost Consideration. Journal of Consumer Research, 38. DOI: 10.1086/660045.

Thirlby, G. (1946). The Ruler, South African Journal of Economics (1946). Reprinted in Buchanan, J. \& Thirlby, E. D. L. S. E. Essays on cost, The London School of Economics and Political Science.

Watts, R. and Zimmerman, J. (1990). Positive Accounting Theory: A Ten Year Perspective. Accounting Review, 131-56.

Waweru, N. M., Munyoki, E. \& Uliana, E. O. (2008). The effects of behavioral factors in investment decisionmaking: a survey of institutional investors operating at the Nairobi Stock Exchange. International Journal of Business and Emerging Markets, 1(1), 24-41.

Zauberman, G. \& Lynch, J. G. Jr. (2005). Resource Slack and Propensity to Discount Delayed Investments of Time versus Money. Journal of Experimental Psychology: General, 134(1), 23-37.

Zhang, N. (2013). Cultural Differences In Opportunity Cost Consideration. A thesis submitted to the Department of Psychology in conformity with the requirements for the degree of Master of Science Queen's University Kingston, Ontario, Canada. 